\title{
Monitoring and predicting the risk of violence in residential facilities. No difference between patients with history or with no history of violence
}

\author{
Giovanni de Girolamo ${ }^{a}$, Chiara Buizza ${ }^{\text {b }}$, Davide Sisti ${ }^{c}$, Clarissa Ferrari ${ }^{d}$, Viola Bulgari a, e, \\ Laura Iozzino $^{\mathrm{f}}$, Maria Elena Boero ${ }^{\mathrm{g}}$, Giuseppe Cristiano ${ }^{\mathrm{h}}$, Alessandra De Francesco ${ }^{\mathrm{g}}$, \\ Gian Marco Giobbio ${ }^{\text {h, }}$, Paolo Maggi ${ }^{\text {, }}$, Giuseppe Rossi ${ }^{j}$, Beatrice Segalini ${ }^{\text {h }}$, \\ Valentina Candini $^{\mathrm{a}, \mathrm{k},}$, , for the VIORMED-1 Group ${ }^{1}$ \\ ${ }^{a}$ Psychiatric Epidemiology and Evaluation Unit, Saint John of God Clinical Research Center, Brescia, Italy \\ ${ }^{\mathrm{b}}$ Department of Clinical and Experimental Sciences, University of Brescia, Italy \\ ${ }^{\mathrm{c}}$ Institute of Biomathematics, University of Urbino, Italy \\ ${ }^{\mathrm{d}}$ Service of Statistics, Saint John of God Clinical Research Center, Brescia, Italy \\ e PhD School in Psychology, Catholic University of the Sacred Heart, Milan, Italy \\ ${ }^{\mathrm{f}}$ Department of Neurosciences, Biomedicine and Movement Sciences, University of Verona, Italy \\ ${ }^{\mathrm{g}}$ Rehabilitation Hospital Beata Vergine Della Consolata, Torino, Italy \\ ${ }^{\text {h }}$ Villa Sant'Ambrogio Hospital, Milan, Italy \\ i Sacro Cuore di Gesù Center, Milan, Italy \\ j Psychiatric Unit, Saint John of God Clinical Research Center, Brescia, Italy \\ ${ }^{\mathrm{k}}$ Department of General Psychology, University of Padova, Italy
}

\section{A R T I C L E I N F O}

\section{Article history:}

Received 3 March 2016

Received in revised form

11 May 2016

Accepted 20 May 2016

\section{Keywords:}

Violence

Mental disorders

Recidivism

Residential facilities

\begin{abstract}
A B S T R A C T
Background: Most people with mental disorders are not violent. However, the lack of specific studies in this area and recent radical changes in Italy, including the closure of six Forensic Mental Hospitals, has prompted a more detailed investigation of patients with aggressive behaviour.

Aims: To compare socio-demographic, clinical and treatment-related characteristics of long-term inpatients with a lifetime history of serious violence with controls; to identify predictors of verbal and physical aggressive behaviour during 1-year follow-up.

Methods: In a prospective cohort study, patients living in Residential Facilities (RFs) with a lifetime history of serious violence were assessed with a large set of standardized instruments and compared to patients with no violent history. Patients were evaluated bi-monthly with MOAS in order to monitor any aggressive behaviour.

Results: The sample included 139 inpatients, 82 violent and 57 control subjects; most patients were male. The bi-monthly monitoring during the 1 -year follow-up did not show any statistically significant differences in aggressive behaviour rates between the two groups. The subscale explaining most of the MOAS total score was aggression against objects, although verbal aggression was the most common pattern. Furthermore, verbal aggression was significantly associated with aggression against objects and physical aggression.

Conclusions: Patients with a history of violence in RFs, where treatment and clinical supervision are available, do not show higher rates of aggressiveness compared to patients with no lifetime history of violence. Since verbal aggression is associated with more severe forms of aggression, prompt intervention is warranted to reduce the risk of escalation.
\end{abstract}

() 2016 Elsevier Ltd. All rights reserved.

\footnotetext{
* Corresponding author. Saint John of God Clinical Research Center, Via Pilastroni, 4, 25125 Brescia, Italy.

E-mail address: vcandini@fatebenefratelli.eu (V. Candini).

1 The VIORMED-1 Group includes the following members: Suor Andreose, M.D., Pasquale Basso, M.D., Rossella Beneduce, M.D., Pietro Bertolotti, M.D., Vanda Braida, M.D.,

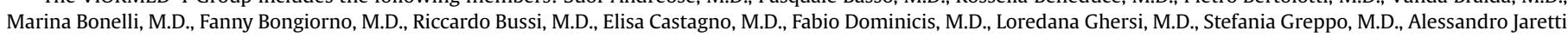

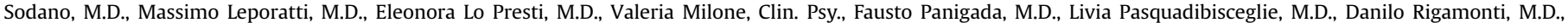
Luciana Rillosi, M.D.
} 


\section{Introduction}

The risk of violence posed by patients with severe mental disorders has long been a hot topic. In the general population, the attributable risk due to mental disorders is small compared to other risks of violence. By using population registers, Fazel and Grann (2006) found the population attributable risk fraction of severe mental illness on violent criminality to be no more than $5 \%$. In other words, mental illness is a limited source of violence in the community. However, violence committed by people suffering from mental disorders tends to gain disproportionate media coverage, creating an exaggerated sense of personal risk (Arboleda-Flòrez, 2009), and this underlines the need for proper management of patients at risk of violent behaviour.

In Italy there have been six Forensic Mental Hospitals (FMHs) with a total population of around 1400 individuals. Recent laws (n. 9/2012 and 81/2014) set the deadline of 31 March 2015 for the gradual discharge of all patients from FMHs and their relocation to special high-security units, with no more than 20 beds each. In addition, many patients at lower risk of reoffending, will be cared for by ordinary Mental Health Departments (DMHs). This change will involve increasing legal responsibility of both individual psychiatrists and DMHs and will also require a substantial organizational change for Mental Health Services compared to the past.

Given this radical change and given the paucity of Italian studies in this area, we set up a specific study aimed to verify whether psychiatric patients with a history of violence and living in Residential Facilities (RFs) are really more aggressive than inpatients with no history of violence. Our main aims were: (a) to assess the socio-demographic, clinical and treatment-related characteristics of patients living in RFs with a lifetime history of interpersonal violence, and compare them with controls with no history of violence; (b) to find predictors of aggressive and violent behaviour in patients assessed bi-monthly with the Modified Overt Aggression Scale (MOAS) over a 1-year follow-up.

\section{Materials and methods}

\subsection{Study design}

This prospective cohort study involved patients living in different RFs in four sites (Cernusco, Pavia, Brescia and Turin) in Northern Italy. All patients with a history of severe interpersonal violence (named 'violent patients'), living in these RFs in the index period May-September 2013, were recruited by treating clinicians. Furthermore, patients with no history of violence, similar by age, gender and primary diagnosis (including co-morbidity with substance or alcohol addiction), were identified as a control group.

\subsection{Patient inclusion and exclusion criteria}

Violent patients had to meet one or more of the following criteria: (i) to be admitted at least once to a FMH for any violent acts against people; (ii) to be arrested at least once for any violent act against people; (iii) to have a documented lifetime history of violent acts against people (as reported in the official clinical records). The control group included patients who did not meet any of these three conditions. Exclusion criteria were being older than 65 years and having a primary diagnosis of organic mental disorder. The study was approved by the relevant Ethics Committees and all participants provided written informed consent.

\subsection{Baseline assessment}

A Patient Schedule addressing socio-demographic characteristics, social relationships, leisure activities, socioeconomic status, clinical and treatment-related features, plus a specific section (only for violent patients) concerning their history of violence was filled in for each patient recruited. The SCID-I and SCID-II (First et al., 2002,1997) were administered in order to confirm clinical diagnoses.

Psychopathology and psychosocial functioning were assessed by the following: the Brief Psychiatric Rating Scale (BPRS) (Ventura et al., 1993), the Personal and Social Performance (PSP) scale, a modified version of the DSM-IV Social and Occupational Functioning Assessment Scale (SOFAS) (Morosini et al., 2000) and the Specific Levels Of Functioning (SLOF) (Harvey et al., 2011).

Aggression and impulsivity were evaluated by the following instruments: (a) the Brown-Goodwin Lifetime History of Aggression (BGLHA), an 11-item questionnaire assessing lifetime aggressive behaviour across 2 stages of life (adolescence and adulthood) by directly aiming how many times the aggressive behaviour occurred for each item (Brown et al., 1979); (b) the Buss-Durkee Hostility Inventory (BDHI), a 75-item questionnaire developed to assess 8 subscales related to hostility and negative affect (Buss and Durkee, 1957); (c) the Barratt Impulsiveness Scale (BIS-11), a 30item, 4-point Likert scale questionnaire that investigates personality and behavioral impulsiveness, with scores ranging from 30 to 120 (Barratt, 1965); (d) the State-Trait Anger Expression Inventory 2 (STAXI-2), which includes six scales plus an Anger Expression Index, an overall measure of total anger expression (Spielberger et al., 1985).

Patients' insight was assessed by the Insight scale (Marková et al., 2003), which provides a total score ranging from 0 (no insight) to 30 (full insight).

All research assistants underwent centralised instrument administration- and rating training conducted by clinicians with a specific experience in this area.

\subsection{Bi-monthly monitoring of violent behaviour}

Every two weeks, during the 1-year follow-up after the baseline assessment, the treating clinician or the patient's case manager filled in the MOAS (Margari et al., 2005) for each patient involved in the study. All assessors were very familiar with patients and had daily contact with them. The MOAS included 4 subscales of aggression: verbal, physical, against objectives and self-harm behaviour. Here, we focused only on the first three subscales. A score from 0 to 4 is assigned to each act: 0 indicating no aggressive behaviour and higher scores increasing severity. The score in each category is multiplied by a factor assigned to that category; 1 for verbal aggression, 2 for aggression against objects, 3 for aggression against self and 4 for aggression against other people. So, the total weighted score ranges from 0 (no aggression) to 40 (maximum grade of aggression). We will subsequently refer to the weighted MOAS score simply as the MOAS score.

\subsection{One-year follow-up}

Changes in the patients' clinical and psycho-social conditions were re-evaluated with the BPRS and PSP. For patients discharged to other accommodations or discharged home during follow-up, the researchers contacted their treating psychiatrist and asked him/her to fill in the MOAS fortnightly.

\subsection{Statistical analyses}

Categorical data were analysed in inter-group comparisons with $\chi^{2}$, or Fisher's exact test, when appropriate $(\mathrm{n}<5$ in any cell in binary comparison). The Cramer values were reported as association index. Student t-test was used to compare quantitative 
variables. The accordance between categorical variables, clinicians' prediction and home discharge were quantified using Cohen's kappa co-efficient. Non parametric tests were used for comparing non-Gaussian variables.

Monitoring of violent behaviour was performed by analysing the MOAS total score and MOAS subscales along all the 24 timepoints during follow-up. Considering the non-Gaussian (skewed and zero-inflated) distribution of MOAS score, generalized estimating equation (GEE) models with tweedie distribution and loglink function were adopted to analyse MOAS repeated measures. Similarly, the relation between the total scores of MOAS subscales (mean across the 24 time-points) were investigated by generalized linear models with tweedie distributions. Goodness of fit of the models were evaluated by Akaike information index (AIC: the lower index value, the better the model fit). Finally, an analysis of predictors of violent behaviour was carried out through generalized linear models (with tweedie distribution and log-link function) with the MOAS mean total score as a dependent variable, and continuous and categorical measures as independent variables.

All tests were two-tailed, with statistically significant level set at $p=0.05$. All data were coded and analysed using the Statistical Package for Social Science (SPSS, version 21) for Windows (Chicago, Illinois 60,606, USA), and R: A language and environment for statistical computing, (R Core Team, 2015), R Foundation for Statistical Computing, Vienna, Austria.

\section{Results}

A total of 139 inpatients with a primary diagnosis of mental disorders met the study entry criteria: 82 had a lifetime history of severe aggression against people (violent patients) and 57 were controls. Another 10 patients were contacted, but refused to participate in the study ( 7 with a history of violence). The mean age of the violent patients was 44.9 years $(S D=11.4)$ compared to 46.7 $(\mathrm{SD}=9.5)$ for the controls.

With regard to RF characteristics and restrictiveness, they have similar features in terms of coverage by medical staff (24-h cover), number of beds (generally, each RF hosts up to 20 patients, with two patients in each room), and the average number of treating staff (i.e. psychiatrists, nurses, vocational therapists). When we controlled for all environmental and staff characteristics, no differences were found between different sites; in particular, with regard to the average number of treating staff per $\mathrm{RF}$, there were no between-site differences (Cernusco: $9.1 \pm 2.0$ average number of staff; Pavia: $10.5 \pm 1.5$; Brescia: $8.3 \pm 1.5$; Turin: $11.5 \pm 2.3$; $p=0.079$ ). In all RFs patients were free to get out during the daytime, upon agreement with the staff.

\subsection{The sample's socio-demographic characteristics}

More patients in the violent group (38.3\%) were employed as compared to controls (19.6\%; $\chi^{2}=0.445, p=0.020$ ). As expected, $51.2 \%$ of violent patients were admitted to the $\mathrm{RF}$ from a prison or a $\mathrm{FMH}$, compared to none in the control group $\left(\chi^{2}=0.618, p=0.001\right)$ (see Table 1).

Table 2 shows the clinical and treatment-related characteristics of the two groups.

The most common primary diagnosis was schizophrenia, with a lifetime history of alcohol abuse. There was also a relevant proportion of patients meeting criteria for personality disorders and the difference between the two groups was statistically significant: $79.3 \%$ in the violent group versus $63.2 \%$ in the control $\left(\chi^{2}=4.39\right.$, $p=0.036$ ).

No significant difference (Mann-Whitney $p=0.221$ ) between groups was detected in terms of length of stay in RF: 840 days
$($ median $=314)$ for violent patients, and 897 days $($ median $=484)$ for the control group.

\subsection{Clinicians' prediction}

Clinicians were also asked to predict the patient's setting of care at the end of the 1-year follow-up. Surprisingly, treating clinicians predicted a higher percentage of patients discharged home in the violent group compared to control patients (respectively $23.2 \%$ compared to $8.8 \%$; V Cramer $=0.315, p=0.002$ ). Indeed, during the 1-year follow-up there was a higher percentage of home discharges among violent patients (44.4\% versus $30.8 \%$ among the controls). We then analysed the concordance between clinicians' predictions and real home discharge of each patient and we found a moderate concordance (Cohen's $\mathrm{K}=0.52, p<0.001$ ). In particular, clinicians' predictions were more accurate for patients not discharged home (108 patients were not discharged home versus 115 predicted, with a $93.9 \%$ of agreement). On the contrary, the agreement was considerably lower for predictions of home discharge (13 patients were discharged home versus 24 predicted, with $54.2 \%$ agreement).

\subsection{Aggressiveness and impulsivity}

Table 3 shows the group comparisons on assessment of aggressive and impulsive behaviour.

Concerning the BGLHA, there was a statistically significant difference between the two groups, indicating a more severe history of lifetime aggressive behaviour in violent patients during adolescence and adulthood. For the BDHI and the STAXI-2, there were few statistically significant differences in ratings.

\subsection{Sample's clinical characteristics}

Table 4 shows the group comparisons in psychopathology and psychosocial functioning.

At baseline, there were no differences in the mean BPRS total score between the two groups. A statistically significant difference was found only for the withdrawal subscale (mean score: 11.0, $\mathrm{SD}=5.0$ for the controls versus $8.4, \mathrm{SD}=4.3$ for the violent patients; $p=0.001$ ), which includes 'emotional withdrawal', 'motor retardation' and 'blunted affect', with higher scores pointing to a higher level of symptomatology. Violent patients were also characterized by a higher level of psycho-social functioning (PSP mean score $=44.5, \mathrm{SD}=17.3$ ) than controls (PSP mean score $=38.5$, $\mathrm{SD}=15.0, p=0.037)$. On the contrary, there were no statistically significant group differences regarding the SLOF, although subjects with a history of violence reported higher scores on almost all SLOF domains. With regard to patients' insight, our results did not show any differences between the two groups. The mean total score for the violent group was $12.3(\mathrm{SD}=6.9)$ as compared to $13.6(\mathrm{SD}=7.1)$ for the control group.

\subsection{Psychotropic medications}

At baseline, $94.2 \%$ patients were on psychotropic medication, although for $8(5.8 \%)$ subjects these data were missing. For all drug classes (antipsychotic drugs, mood stabilizers, benzodiazepines), there were no statistically significant differences between the two groups. The percentage of violent patients (36.6\%) receiving mood stabilizers was similar to that of the control group $(35.1 \%$, $p=0.856$ ). Similarly, $51.2 \%$ of violent patients were receiving two or more anti-psychotics compared to $40.4 \%$ of the control group ( $p=0.172$ ) and $23.7 \%$ of violent patients were receiving two or more benzodiazepines compared to $38.2 \%$ of controls $(p=0.181$ ). 
Table 1

Sociodemographic characteristics of violent patients and controls at baseline.

\begin{tabular}{|c|c|c|c|c|}
\hline & Violent patients $(\mathrm{N}=82) \mathrm{N}(\%)$ & Controls $(\mathrm{N}=57) \mathrm{N}(\%)$ & Test $^{\mathrm{a}}$ & p-value \\
\hline \multicolumn{5}{|l|}{ Gender } \\
\hline Male & $74(90.2)$ & $47(82.5)$ & 0.114 & 0.179 \\
\hline Female & $8(9.8)$ & $10(17.5)$ & & \\
\hline \multicolumn{5}{|l|}{ Nationality } \\
\hline Italian & $76(92.7)$ & $56(98.2)$ & 0.122 & 0.150 \\
\hline Others & $6(7.3)$ & $1(1.8)$ & & \\
\hline \multicolumn{5}{|l|}{ Age } \\
\hline $18-33$ & $11(13.4)$ & $5(8.8)$ & 0.09 & 0.558 \\
\hline $34-49$ & $38(46.3)$ & $31(54.4)$ & & \\
\hline $50-64$ & $33(40.2)$ & $21(36.8)$ & & \\
\hline \multicolumn{5}{|l|}{ Marital status } \\
\hline Married or cohabiting & $5(6.1)$ & $3(5.3)$ & 0.201 & 0.232 \\
\hline Single & 77 (93.9) & $54(94.7)$ & & \\
\hline \multicolumn{5}{|l|}{ Education } \\
\hline Low level & $67(81.7)$ & $45(79.0)$ & 0.165 & 0.584 \\
\hline Medium-high level & $15(18.3)$ & $12(21.0)$ & & \\
\hline \multicolumn{5}{|l|}{ Occupation } \\
\hline Employed & $31(38.3)$ & $11(19.6)$ & 0.445 & 0.020 \\
\hline Unemployed & $50(61.7)$ & $45(80.4)$ & & \\
\hline \multicolumn{5}{|l|}{ Admission source } \\
\hline From home & $11(13.4)$ & $19(33.3)$ & 0.618 & 0.001 \\
\hline From a FMH & $22(26.8)$ & $0(0.0)$ & & \\
\hline From a prison & $20(24.4)$ & $0(0.0)$ & & \\
\hline Other RF & $29(35.4)$ & $38(66.7)$ & & \\
\hline \multicolumn{5}{|l|}{ Economic independence } \\
\hline Yes & $13(15.9)$ & $15(26.3)$ & 0.128 & 0.130 \\
\hline No & $69(84.1)$ & $42(73.7)$ & & \\
\hline \multicolumn{5}{|l|}{ Social relationships } \\
\hline Yes & $59(72.0)$ & $43(75.4)$ & 0.039 & 0.647 \\
\hline No & $23(28.0)$ & $14(24.6)$ & & \\
\hline \multicolumn{5}{|c|}{ Time spent doing nothing } \\
\hline Less than $6 \mathrm{~h}$ per day & $22(26.8)$ & $24(42.1)$ & 0.161 & 0.165 \\
\hline More than $6 \mathrm{~h}$ per day & $60(73.2)$ & $33(57.9)$ & & \\
\hline
\end{tabular}

a Standardized value of V Cramer.

\subsection{Follow-up clinical assessment}

At 1-year follow-up, the level of psychopathology was stable, as shown by the BPRS scores, which changed only marginally. There was only a statistically significant difference between the two groups in the withdrawal subscale, already recorded at baseline. Similar considerations were applicable to the PSP (see Table 4).

\subsection{Aggressive and violent behaviour during the 1-year follow-up}

With regard to the monitoring of MOAS total scores during the 1-year follow-up, there were no statistically significant differences between the mean across time of the two groups (mean $=0.5$, $\mathrm{SD}=0.8$, median $=0.2$ for violent group and mean $=0.3, \mathrm{SD}=0.7$ and median $=0$ for controls). We did observe some differences between the two groups which, however, were not statistically significant (Fig. 1). In particular, violent patients showed higher weighted total scores in the first four months (8 time-points). In order to understand this result more in detail, we analysed weighted total scores for each of the four study sites (Fig. 1s). There were two sites (Cernusco and Pavia) with many episodes of aggressive behaviour among violent patients and almost none in the control sample. Differently, in the other two sites (Brescia and Turin), there were no evidence of differences between the two groups (neither in Brescia site where the difference observed in the first four months was no significant).

The most common aggressive behaviour displayed by patients was verbal aggression: $54 \%$ of patients were verbally aggressive at least once during the 1-year follow-up, compared with $25.9 \%$ of patients scoring $\geq 1$ for aggression against objects, and $19.4 \%$ for inter-personal violence. However, if we consider the scores for the different subscales, no significant differences were detected between the two groups, basically due to the large amount of variability within group scores (Fig. 2).

Similarly, no statistically significant difference emerged when comparing violent patients discharged at home versus violent patients not discharged or versus controls (Fig. 2s).

\subsection{Relationship between different types of aggression and violence}

Generalized linear models performed to analyse the relationship between MOAS subscales (mean of unweighted scores across follow-up time) showed that the subscale which explained to a larger extent the MOAS total score variability was aggression against objects (standardized beta coefficient $=1.39$, AIC $=653$ ), followed by physical and verbal aggression (respectively with beta $=1.35$, AIC $=681$; beta $=1.15$, AIC $=698$ ).

With regard to the relationship between the three subscales, verbal aggression was a significant predictor of aggression against objects (beta $=1.20, p<0.001$ ) and of physical aggression (beta $=1.18, p<0.001$, with AIC indexes of 250 and 300 respectively), while aggression against objects was a significant predictor (beta $=1.51, p<0.001)$ of interpersonal violence $($ AIC $=244)$.

\subsection{Predictors of violent behaviour during the 1-year follow-up}

In order to identify occurrence predictors of new episodes of violence during follow-up, we considered variables shown in previous studies to be associated to the risk of violence, such as gender, education, occupation, diagnosis of schizophrenia, functioning, substance use and lifetime history of violence (Iozzino et al., 2015). We also included variables that we found associated with the 
Table 2

Clinical and treatment-related characteristics of violent patients and controls.

\begin{tabular}{|c|c|c|c|c|}
\hline & Violent $(\mathrm{N}=82) \mathrm{N}(\%)$ & Controls $\mathrm{N}=57 \mathrm{~N}(\%)$ & Test $^{\mathrm{a}}$ & p-value \\
\hline Illness duration (Years) (mean, SD) & $20.1( \pm 10.5)$ & $23.3( \pm 10.2)$ & -1.70 & 0.092 \\
\hline Age of first contact with DMHs (Years) (mean, SD) & $28.7( \pm 11.4)$ & $25.7( \pm 7.8)$ & 1.504 & 0.135 \\
\hline \multicolumn{5}{|l|}{ Lifetime Compulsory Admissions } \\
\hline None & $9(12.0)$ & $17(37.0)$ & 0.503 & 0.001 \\
\hline $1-3$ & $60(80.0)$ & $39(63.0)$ & & \\
\hline$\geq 4$ & $6(8.0)$ & $0(0)$ & & \\
\hline \multicolumn{5}{|l|}{ Primary Diagnosis } \\
\hline Schizophrenia & $50(61.0)$ & $37(64.9)$ & 0.223 & 0.228 \\
\hline Personality disorder & $16(19.5)$ & $10(17.6)$ & & \\
\hline Other & $16(19.5)$ & $10(17.5)$ & & \\
\hline \multicolumn{5}{|l|}{ Meeting criteria for personality disorder } \\
\hline Yes & $65(79.3)$ & $36(63.2)$ & 4.39 & 0.036 \\
\hline No & $17(20.7)$ & $21(36.8)$ & & \\
\hline \multicolumn{5}{|l|}{ Lifetime use of Alcohol } \\
\hline Yes & $34(43.6)$ & $31(55.4)$ & 1.807 & 0.179 \\
\hline No & $44(56.4)$ & $25(44.6)$ & & \\
\hline \multicolumn{5}{|l|}{ Lifetime use of Cannabinoids } \\
\hline Yes & $23(29.9)$ & $11(19.6)$ & 0.116 & 0.182 \\
\hline No & $54(70.1)$ & $45(80.4)$ & & \\
\hline \multicolumn{5}{|l|}{ Lifetime use of Stimulants } \\
\hline Yes & $19(25.0)$ & $8(14.3)$ & 0.131 & 0.131 \\
\hline No & $57(75.0)$ & $48(85.7)$ & & \\
\hline \multicolumn{5}{|l|}{ Lifetime use of Opioids } \\
\hline Yes & $15(20.3)$ & $6(10.7)$ & 0.129 & 0.143 \\
\hline No & 59 (79.7) & $50(89.3)$ & & \\
\hline \multicolumn{5}{|l|}{ Lifetime use of Hallucinogens } \\
\hline Yes & $12(15.6)$ & $9(16.1)$ & 0.003 & 0.974 \\
\hline No & $63(84.4)$ & $48(83.9)$ & & \\
\hline \multicolumn{5}{|l|}{ Social Support } \\
\hline Available & $48(62.3)$ & $31(55.0)$ & 0.120 & 0.572 \\
\hline Not available & $29(37.7)$ & $26(45.0)$ & & \\
\hline \multicolumn{5}{|l|}{ Appropriateness of the accommodation } \\
\hline Appropriate & $66(80.5)$ & $52(91.2)$ & 0.070 & 0.371 \\
\hline Inappropriate & $16(19.5)$ & $5(8.8)$ & & \\
\hline \multicolumn{5}{|c|}{ Clinician's prediction about the stay of the patient after 1-year } \\
\hline Not discharged & $37(45.1)$ & $37(64.9)$ & 0.315 & 0.002 \\
\hline Discharged to another RF & $26(31.7)$ & $15(26.3)$ & & \\
\hline Home discharged & $19(23.2)$ & $5(8.8)$ & & \\
\hline \multicolumn{5}{|l|}{ Destination of discharge } \\
\hline At home & $16(44.4)$ & $4(30.8)$ & 0.160 & 0.535 \\
\hline Other RF & $19(52.8)$ & $9(69.2)$ & & \\
\hline Prison & $1(2.8)$ & $0(0.0)$ & & \\
\hline \multicolumn{5}{|l|}{ Discharged during the 1 year follow-up } \\
\hline No & $46(56.1)$ & $44(77.2)$ & 0.210 & 0.013 \\
\hline Yes & 36 (43.9) & $13(22.8)$ & & \\
\hline
\end{tabular}

${ }^{a}$ Standardized value of V Cramer, except for the first two variables where t-tests were used.

violent group (BDHI total score, BGLHA total score, and STAXI-2 anger expression-out). We defined as "new violent" a patient with a total MOAS score (sum across the 24 time-points) $\geq 3$.

Patients with a total weighted MOAS score $>3$ during the 1 -year follow-up were $46 \%(\mathrm{~N}=64)$ of the sample. None of the sociodemographic and clinical characteristics stood out as a significant predictor of new violent behaviour, with the only exception of PSP, providing a summary score for the level of functioning (beta coefficient $=-0.54, p<0.001$, indicating that a higher score in social functioning was associated with a lower total MOAS score).

\section{Discussion}

This work contributes to the study of the risk of violence in an era where the forensic system in Italy is undergoing radical change and the care for offenders will switch to ordinary DMHs and facilities run by them, such as RFs or high security units. Our sample can be considered representative of an average sample of patients with a history of violence treated by DMHs and living in RFs. The vast majority $(80 \%)$ had committed physical assaults of medium gravity, while a minority (20\%) were responsible for very severe acts of violence, including murder or attempted murder. More than half of the sample had been referred to RFs by a FMH or by a prison. In $1 / 3$ of cases, the victim was a family member, again highlighting the high burden suffered by family members even with regard to the risk of physical violence by the ill relative.

\subsection{Patients' profiles and history of violence}

In line with a previous study, these data show that patients with a past history of violence seem to have better psycho-social functioning and show a milder degree of emotional withdrawal and blunted affect compared to patient with no history of violence (Candini et al., 2015; Fioritti et al., 2006). Violent inpatients are also more likely to be employed, to meet criteria for personality disorders and to have a lifetime history of compulsory admissions; they were identified by treating clinicians as more likely to be discharged home. It might be that violent patients were admitted to RFs because of their risk of violence, whereas non-violent patients were referred because of their low functioning and poor ability to care for themselves. 
Table 3

Rating scales for the assessment of aggressive and impulsive behaviour.

\begin{tabular}{|c|c|c|c|}
\hline & Violent patients $(\mathrm{N}=82)$ mean $(\mathrm{SD})$ & Controls $(\mathrm{N}=57)$ mean $(\mathrm{SD})$ & T-statistics (p-value) \\
\hline \multicolumn{4}{|l|}{ BDHI } \\
\hline Assault & $4.30(2.33)$ & $3.29(1.97)$ & $2.71(0.008)$ \\
\hline Indirect aggression & $4.29(1.90)$ & $3.96(1.80)$ & $1.00(0.319)$ \\
\hline Irritability & $5.12(2.48)$ & $4.41(2.48)$ & $1.62(0.108)$ \\
\hline Negativism & $3.04(1.46)$ & $2.54(1.57)$ & $1.88(0.063)$ \\
\hline Resentment & $3.49(1.98)$ & $3.27(1.69)$ & $0.71(0.481)$ \\
\hline Suspicion & $4.86(2.41)$ & $4.45(2.18)$ & $1.02(0.307)$ \\
\hline Verbal aggression & $6.78(2.38)$ & $5.89(2.59)$ & $2.01(0.046)$ \\
\hline Guilt & $5.03(2.33)$ & $4.75(2.24)$ & $0.69(0.492)$ \\
\hline Total score & $36.9(12.3)$ & $32.5(11.4)$ & $2.09(0.039)$ \\
\hline \multicolumn{4}{|l|}{ BIS-11 } \\
\hline Cognitive impulsiveness & $16.07(4.50)$ & $17.03(4.22)$ & $-1.27(0.206)$ \\
\hline Motor impulsiveness & 22.01 (4.99) & $22.05(5.51)$ & $-0.04(0.965)$ \\
\hline Non-planning impulsiveness & $27.97(6.00)$ & $28.10(6.08)$ & $-0.12(0.806)$ \\
\hline Total score & $66.06(12.25)$ & $67.19(13.11)$ & $-0.51(0.611)$ \\
\hline \multicolumn{4}{|l|}{ STAXI-2 } \\
\hline State anger & $18.6(6.6)$ & $18.8(8.6)$ & $-0.2(0.854)$ \\
\hline Feeling angry & $6.7(2.6)$ & $6.6(3.3)$ & $0.1(0.900)$ \\
\hline Feel like expressing anger verbally & $6.1(2.4)$ & $6.1(2.4)$ & $-0.7(0.500)$ \\
\hline Feel like expressing anger physically & $5.8(2.4)$ & $5.8(2.4)$ & $0.1(0.952)$ \\
\hline Trait anger & $17.5(6.2)$ & $16.6(6.3)$ & $0.8(0.423)$ \\
\hline Angry temperament & $6.5(2.4)$ & $6.2(2.6)$ & $0.6(0.556)$ \\
\hline Angry reaction & $7.7(3.2)$ & $7.4(3.1)$ & $0.6(0.549)$ \\
\hline Anger expression-out & $15.5(5.7)$ & $13.1(4.4)$ & $2.6(0.009)$ \\
\hline Anger expression-in & $17.8(5.9)$ & $16.9(4.6)$ & $1.0(0.334)$ \\
\hline Anger control-out & $19.7(5.7)$ & $19.0(5.1)$ & $0.8(0.443)$ \\
\hline Anger control-in & $22.5(6.1)$ & $21.5(6.3)$ & $1.0(0.341)$ \\
\hline Anger expression Index & $39.1(13.4)$ & $37.6(14.4)$ & $0.6(0.526)$ \\
\hline \multicolumn{4}{|l|}{ BGLHA } \\
\hline Total score & $40.5(13.5)$ & $34.9(12.0)$ & $2.5(0.014)$ \\
\hline
\end{tabular}

Table 4

Clinical symptoms and psychosocial functioning of violent patients and controls.

\begin{tabular}{|c|c|c|c|c|}
\hline & \multicolumn{2}{|l|}{ Baseline } & \multicolumn{2}{|l|}{ Follow-up } \\
\hline & Violent patients mean (SD) & Controls mean (SD) & Violent patients mean (SD) & Controls mean (SD) \\
\hline \multicolumn{5}{|l|}{ BPRS } \\
\hline Total score & $50.2(24.2)$ & $57.0(19.1)$ & $51.7(24.7)$ & $59.0(18.8)$ \\
\hline Anxiety-Depression & $10.1(4.4)$ & $10.9(4.0)$ & $10.2(4.3)$ & $11.5(4.0)$ \\
\hline Hostility-Suspicion & $7.5(5.1)$ & $7.9(4.7)$ & $7.5(5.0)$ & $8.4(4.8)$ \\
\hline Thinking Disorder & $8.6(4.9)$ & $9.4(4.2)$ & $8.8(4.9)$ & $9.5(4.6)$ \\
\hline Withdrawal & $8.4(4.3)^{a}$ & $11.0(5.0)^{\mathrm{a}}$ & $8.7(4.7)^{\mathrm{b}}$ & $11.4(4.8)^{\mathrm{b}}$ \\
\hline Activity & $6.3(3.0)$ & $6.3(2.5)$ & $6.5(3.0)$ & $6.3(2.6)$ \\
\hline PSP & $44.5(17.3)^{a}$ & $38.5(15.0)^{a}$ & $46.5(19.1)$ & $40.8(16.2)$ \\
\hline \multicolumn{5}{|l|}{ SLOF } \\
\hline Physical functioning & $4.8(0.4)$ & $4.7(0.4)$ & - & - \\
\hline Self-care & $4.3(0.8)$ & $4.0(1.1)$ & - & - \\
\hline Interpersonal relationships & $3.5(0.8)$ & $3.3(0.8)$ & - & - \\
\hline Social acceptability/adjustment & $4.0(1.1)$ & $4.2(1.2)$ & - & - \\
\hline Activities & $3.8(1.0)$ & $3.7(1.0)$ & - & - \\
\hline Work skills & $3.2(1.1)$ & $2.8(1.1)$ & - & - \\
\hline
\end{tabular}

a Statistically significant differences $(\mathrm{p}<0.05$ ) between violent and control patients at the same timepoint (baseline).

b Statistically significant differences $(\mathrm{p}<0.01$ ) between violent and control patients at the same timepoint (follow-up).

\subsection{Impulsiveness and aggressiveness}

The two groups showed very small differences in the ratings of specific scales suited for the assessment of aggressive and impulsive behaviour, and anger. This result might suggest that prolonged exposure to treatment, including active psychopharmacological and psychosocial treatment with an average length of two and a half years (corresponding to the time spent in RFs; for many patients this time was longer), can modify certain behavioral dimensions explored by these scales and cancel out differences, which may have been visible before the start of this treatment.

Nevertheless, the results obtained in these scales are very similar to those of other studies, which have investigated violent behaviour in clinical populations. Our sample's scores are similar to those found in people with personality disorders and in other psychiatric patients (Fossati et al., 2015), but are higher than the average score found in a sample of patients with schizophrenia (Troisi, 2011). However, the BIS-11 total score collected in our study in both groups is much higher than that of healthy controls, who recently reported scores ranging between 37.9 and 42.9 (Reddy et al., 2014; Zhornitsky et al., 2012).

Concerning the history of aggressive behaviour assessed by BGLHA, mean scores were comparable to those of male prisoners in the control group (Bevilacqua et al., 2012; Carli et al., 2010; 


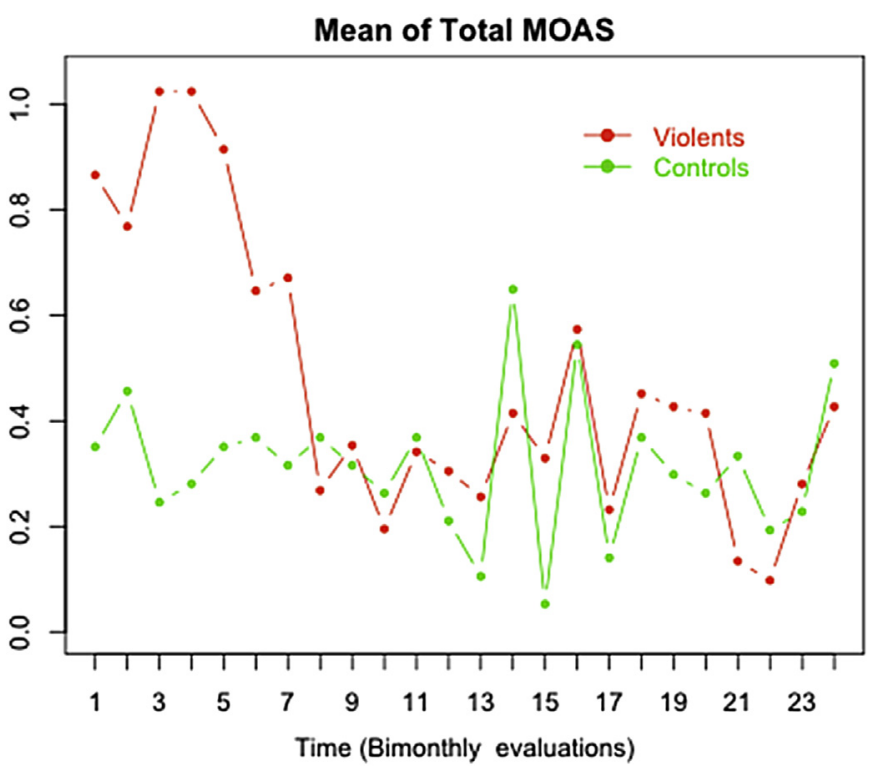

Fig. 1. Total weighted MOAS scores during the 1-year follow-up. This figure represents the trend of aggressive behaviour observed by MOAS in the two groups: violent and controls.

Gorodetsky et al., 2014), while mean scores of the violent group were higher than male prisoners. With regard to the $\mathrm{BDHI}$, the mean scores in the control group were similar to those found in psychiatric inpatients (Dell' Osso et al., 2013), while the violent group scored similar to male prisoners (Carli et al., 2010). Finally, STAXI-2 mean scores of violent and control groups overlapped with mean scores found in the general population sample enrolled for the Italian validation study (Comunian, 2004).

4.3. Are patients with a history of violence and living in RFs more likely to commit violent acts?

Our bi-monthly monitoring with MOAS showed that there were no marked differences between violent and control patients treated in RFs in the rate of aggressive and violent behaviour during the 1year follow-up. Only in the first four months of monitoring did patients with a history of violence show higher scores in verbal aggression. It should be highlighted that adherence to drug treatment (and to psychosocial treatment as well) was ensured for all patients, living in RFs with a 24-h cover. However, violent behaviour was displayed differently in the four sites where the study took place, although these centers were homogeneous from an organizational point of view, and were caring for a very similar casemix of long-stay residential patients. For this reason, the detected differences may be considered due to chance.

\subsection{What predicts violence?}

The only (weak) predictor of occurrence of new episodes of aggressive behaviour in our study was a lower PSP score, providing

\section{Mean of MOAS verbal aggression}

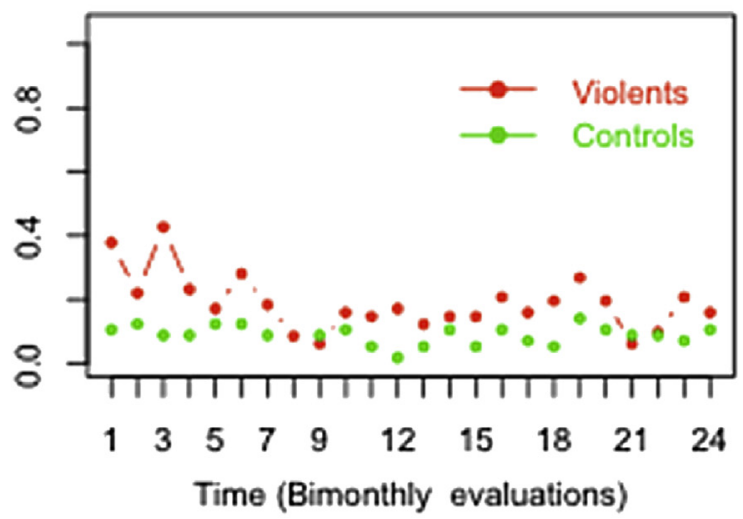

Mean of MOAS self-aggression

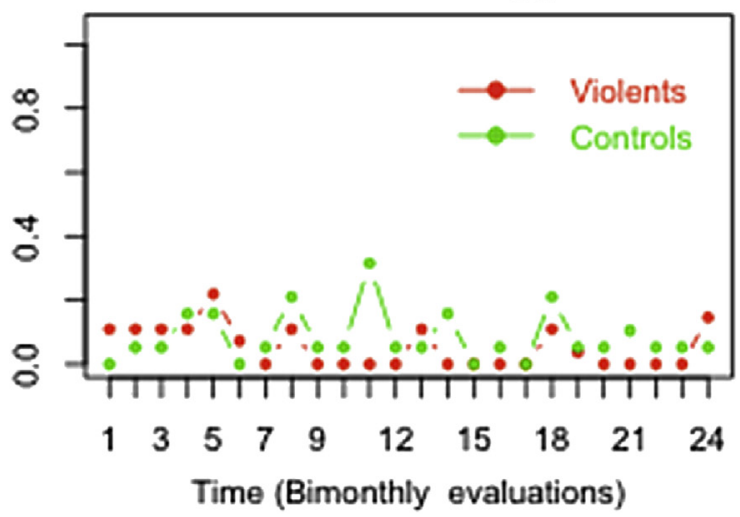

\section{Mean of MOAS aggression against objects}

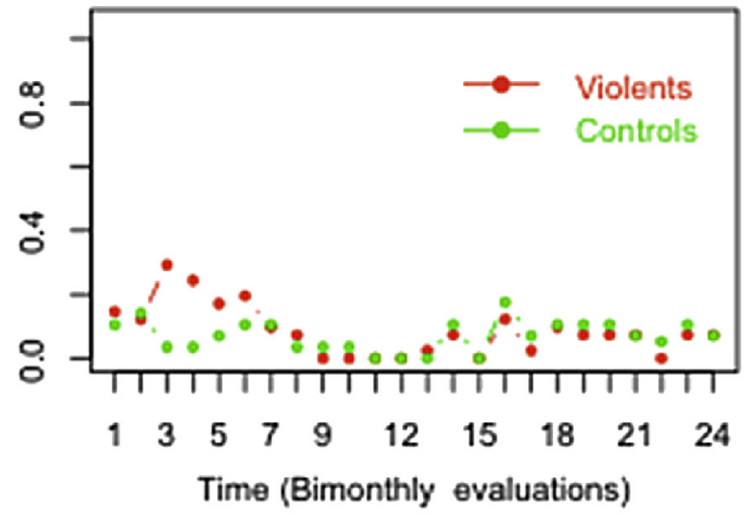

Mean of MOAS physical aggression

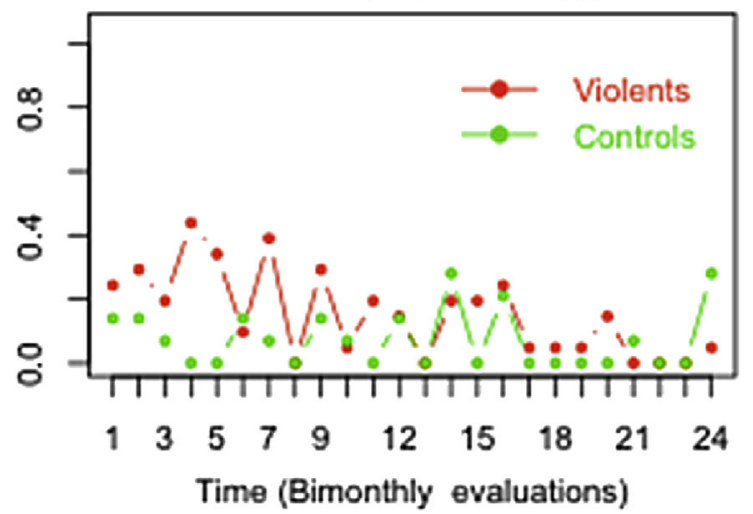

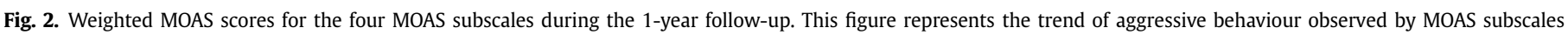
related to four different types of aggression. 
a summary evaluation of social and personal functioning. This finding is also confirmed by a previous study conducted in RFs (Candini et al., 2015) and by a recent meta-analysis focusing on violence by acute psychiatric inpatients (Iozzino et al., 2015). It may be that in samples of patients living in a supportive environment, where treatment is granted, it is difficult to identify variables that predict which patients will behave more aggressively over time. On the other hand, patients with a history of violence were also less withdrawn, as shown by their lower scores on the BPRS withdrawal item. This may suggest that these patients may be more liable to react aggressively to environmental cues which they perceive as unpleasant or threatening. Therefore, they should be actively treated to reduce this risk and strengthen cooperative behaviour.

Finally, patients who showed higher levels of verbal aggression were more likely to commit physical aggression against objects or against other people. Since verbal aggression was the most common aggressive behaviour in our sample, it is important to monitor and manage this behaviour in order to prevent possible escalation.

\subsection{Planning new services for violent patients}

This study provides useful indications for planners and clinicians who have the relevant task of planning, developing and monitoring new facilities for mentally ill offenders in Italy. Patients with a history of interpersonal violence and living in RFs, where treatment and clinical supervision are granted, seem to show more aggression and violence, compared to patients who have never been violent, only to a limited extent. This may mean that intensive treatment is effective in preventing a reiteration of violent behaviour. However, this finding does not necessarily translate to outpatients living in the community: for these patients, compliance with treatment is not granted, the risk of alcohol and substance abuse present, and dropping out of treatment is a frequent event.

\subsection{Limitations}

Our patients' profiles correspond to residents with a high level of clinical and psychopathological impairment and a long history of illness. Moreover, a longer period of observation may lead to higher recidivism among patients with a history of violence and highlight risk factors which are not observable with 1-year follow-up. Finally, we did not directly monitor the use of alcohol and substance abuse during the follow-up period. However, in 24-h staffed RFs, the regular or frequent use of alcohol and substances was very unlikely, if not impossible.

\section{Conclusion}

Our data show that patients with a history of violence living in RFs do not seem to be any more aggressive than patients with no lifetime violent behaviour. The management of mentally ill offenders in the community is one of the great challenges imposed on community psychiatry. Violence by the mentally ill has a profound detrimental effect on public opinion, is associated with stigma and discrimination and poses a great burden on family members, who are often victims of such violence. If community psychiatry is able to prevent violence associated with mental disorders, the full integration of patients and their families would be much easier.

\section{Roles of contributors}

Giovanni de Girolamo and Valentina Candini designed the study, wrote the study protocol and the manuscript, and coordinated the study in all phases.

Chiara Buizza collaborated in data analysis and in writing of the

\section{manuscript.}

Davide Sisti and Clarissa Ferrari performed statistical analyses.

Viola Bulgari, Maria Elena Boero, Alessandra De Francesco, Gian Marco Giobbio, Laura Iozzino, Paolo Maggi, Giuseppe Rossi, and Beatrice Segalini were involved in study coordination, in the selection and assessment of patients and in data analysis.

\section{Funding Source}

The study was funded with the 5 per thousand research funds to the IRCCS Fatebenefratelli.

\section{Conflicts of interest}

None.

\section{Acknowledgement}

The study was funded with the 5 per thousand research funds to the IRCCS Fatebenefratelli.

We would like to thank the following psychiatrists who have kindly collaborated in the project and provided MOAS ratings for enrolled patients: P. Abbate, D. Amodio, D. Beccati, E. Capuzzi, L. Conti, G. Erba, R. Garini, M. Gargiuolo, A. Lastrico, A. Lorini, A. Lusignani, G. Magnani, A. Moro, F. Odone, G. Pancera, M. Patat, G. Romano, C. Saffiotti, G. Seggioli, C. Socrates, S. Surace, P. Verga.

Thanks are also due to Dott. Robert Coates, medical writer and editor (Centro Linguistico Bocconi, University of Milan) for his linguistic revision.

\section{Appendix A. Supplementary data}

Supplementary data related to this article can be found at http:/ dx.doi.org/10.1016/j.jpsychires.2016.05.010.

\section{References}

Arboleda-Flórez, J., 2009. Mental illness and violence. Curr. Opin. Psychiatry 22, 475-476.

Barratt, E.S., 1965. Factor analysis of some psychometric measures of impulsiveness and anxiety. Psychol. Rep. 16, 547-554.

Bevilacqua, L. Carli, V., Sarchiapone, M., George, D.K. Goldman, D., Roy, A Enoch, M.A., 2012. Interaction between FKBP5 and childhood trauma and risk of aggressive behavior. Arch. Gen. Psychiatry 69 (1), 62-70.

Brown, G.L., Goodwin, F.K., Ballenger, J.C., Goyer, P.F., Major, L.K., 1979. Aggression in humans correlates with cerebrospinal fluid amine metabolites. Psychiatry. Res. $1,131-139$

Buss, A.H., Durkee, A., 1957. An inventory for assessing different kinds of hostility. J. Consult. Psychol. 21, 343-349.

Candini, V., Buizza, C., Ferrari, C., Boero, M.E., Giobbio, G.M., Goldschmidt, N. Greppo, S., Iozzino, L., Maggi, P., Melegari, A., Pasqualetti, P., Rossi, G., de Girolamo, G., 2015. Violent behaviour of patients living in psychiatric residential facilities: a comparison of male patients with different violence histories. Int. J. Law. Psychiatry 39, 46-51.

Comunian, L., 2004. Manuale STAXI-2 State-Trait Anger Expression Inventory - 2 Adattamento Italiano. Organizzazioni Speciali, Firenze.

Carli, V., Jovanović, N., Podlesek, A., Roy, A., Rihmer, Z., Maggi, S., Marusic, D. Cesaro, C., Marusic, A., Sarchiapone, M., 2010. The role of impulsivity in selfmutilators, suicide ideators and suicide attempters - a study of 1265 male incarcerated individuals. J. Affect. Disord. 123 (1-3), 116-122.

Dell'Osso, L., Mandelli, L., Carlini, M., Bouanani, S., Rotondo, A., Conversano, C., Serretti, A., Marazziti, D., 2013. Temperamental and genetic predictors of suicide attempt and self-mutilation. Neuropsychobiology 68 (4), 250-257.

Fazel, S., Grann, M., 2006. The population impact of severe mental illness on violent crime. Am. J. Psychiatry 163, 1397-1403.

Fioritti, A., Ferriani, E., Rucci, P., Melega, V., 2006. Characteristics of homicide perpetrators among Italian forensic hospital inmates. Int. J. Law. Psychiatry 29 212-219.

First, M.B., Gibbon, M., Spitzer, R.L., Williams, J.B.W., Benjamin, L.S., 1997. Structured Clinical Interview for DSM-IV Axis II Personality Disorders (SCID-II). American Psychiatric Press, Inc., Washington, D.C.

First, M.B., Spitzer, R.L., Gibbon, M., Williams, J.B.W., 2002. Structured Clinical Interview for DSM-IV-TR Axis I Disorders, Research Version, Patient Edition 
(SCID-I/P). Biometrics Research. New York State Psychiatric Institute.

Fossati, A., Gratz, K.L., Borroni, S., Maffei, C., Somma, A., Carlotta, D., 2015. The relationship between childhood history of ADHD symptoms and DSM-IV borderline personality disorder features among personality disordered outpatients: the moderating role of gender and the mediating roles of emotion dysregulation and impulsivity. Compr. Psychiatry 56, 121-127.

Gorodetsky, E., Bevilacqua, L., Carli, V., Sarchiapone, M., Roy, A., Goldman, D. Enoch, M.A., 2014. The interactive effect of MAOA-LPR genotype and childhood physical neglect on aggressive behaviors in Italian male prisoners. Genes. Brain. Behav. 13 (6), 543-549.

Harvey, P., Raykov, T., Twamley, E., Vella, L., Heaton, R., Patterson, T., 2011. Validating the measurement of real-world functional outcomes: phase I results of the VALERO study. Am. J. Psychiatry 168 (11), 1195-1120.

Iozzino, L., Ferrari, C., Large, M., Nielssen, O., de Girolamo, G., 2015. Prevalence an risk factors of violence by psychiatric acute inpatients: a systematic review and meta-analysis. PloS. One 10 (10), 6 e0128536.

Margari, F., Matarazzo, R., Casacchia, M., Roncone, R., Dieci, M., Safran, S., Fiori, G. Simoni, L., EPICA Study Group, 2005. Italian validation of MOAS and NOSIE: a useful package for psychiatric assessment and monitoring of aggressive behaviours. J. Int. J. Methods. Psychiatr. Res. 14 (2), 109-118.

Marková, I.S., Robertsa, K.H., Gallaghera, C., Boos, H., McKenna, P.J., 2003. Assessment of insight in psychosis: a restandardization of a new scale. Psychiatry. Res. $119(1-2), 81-88$.

Morosini, P.L., Magliano, L., Brambilla, L., Ugolini, S., Pioli, R., 2000. Development, reliability and acceptability of a new version of the DSM-IV social and occupational functioning assessment scale (SOFAS) to assess routine social functioning. Acta. Psychiatr. Scand. 101 (4), 323-329.

Reddy, L.F., Lee, J., Davis, M.C., Altshuler, L., Glahn, D.C., Miklowitz, D., Green, M.F., 2014. Impulsivity and risk taking in bipolar disorder and schizophrenia. Neuropsychopharmacology 39 (2), 456-463.

$\mathrm{R}$ Core Team, 2015. R: a language and environment for statistical computing. $\mathrm{R}$ Foundation for Statistical Computing, Vienna, Austria. URL: https://www.Rproject.org/.

Spielberger, C.D., Johonson, E.H., Russell, S., Crane, R.S., Jacobs, G.A., Worden, T.J., 1985. The experience and expression of anger: construction and validation of an anger expression scale. In: Chesney, M.A., Rosenman, R.H. (Eds.), Anger and Hostility in Cardiovascular and Behavioural Disorder. Hemisphere, New York, pp. 5-30.

Troisi, A., 2011. Low cholesterol is a risk factor for attentional impulsivity in patients with mood symptoms. Psychiatry. Res. 188 (1), 83-87, 30.

Ventura, J., Green, M.F., Shaner, A., Liberman, R.P., 1993. Training and quality assurance with the brief psychiatric rating scale: the drift busters. Int. J. Methods. Psychiatr. Res. 3 (4), 221-244.

Zhornitsky, S., Rizkallah, E., Pampoulova, T., Chiasson, J.P., Lipp, O., Stip, E., Potvin, S. 2012. Sensation-seeking, social anhedonia, and impulsivity in substance use disorder patients with and without schizophrenia and in non-abusing schizophrenia patients. Psychiatr. Res. 200 (2-3), 237-241, 30 